\title{
The Participatory Spectrum Dynamics at the Budgeting Stage in OECD and its Probable Orientation Currently ${ }^{i}$
}

\author{
Ahmet Niyazi Özker \\ Department of Public Finance, Faculty of Economic and Business Administration, Bandirma Onyedi Eylül University, Turkey
}

Copyright $(\mathrm{C} 2018$ by authors, all rights reserved. Authors agree that this article remains permanently open access under the terms of the Creative Commons Attribution License 4.0 International License

\begin{abstract}
In this study, we aim to put forth the participatory budget's structural effects aimed at the future along a participatory spectrum especially for developing countries in OECD. The formation of the structural framework of a participatory budget take important place both in clarifying the internal dynamics of the participatory spectrum and in ensuring structural harmony between the OECD member countries. In this stage, it should be put forth both the redistributive effects of a participatory budget and consultative structural location in its forming process that are related to be improved citizen awareness of councilors in their wards via public contributing. In other hand, this approach contains also the process that is increased resident control over the allocation of some resources. Whichever case is in developed stages for a developing country that regardless of the location, the participatory budget is an audit budget and this public locational position is an indispensable practice of fiscal transparency. This structural importance of participating budget come out from this improved intergenerational institutionally structure to understanding for especially developing countries and OECD has determined some important fact in aimed terms as its member countries for these countries to developing process which are also meaningful in todays. In this context, the participatory budget fact has creative location as a corner stone for developing countries which contribute to improvement a fiscal stability in these countries as a meaningful phenomenon within OECD's general aims.
\end{abstract}

Keywords The Participatory Budgeting, Public Budget Spectrum, Fiscal Stability, Fiscal Transparency, Fiscal Budget Audit

\section{Introduction}

While participatory budgeting is often referred to as a multi-faceted concept in terms of its content, it particularly emphasizes the concept of public communication network and active citizenship in developing countries. In this context, this concept means both active citizenship that is related to financial audit and financial transparency aimed at public budget balances. Nevertheless, it is fact that it can be argued that the concept of participatory budget means that it is far beyond this structural situation for developing countries. It is noteworthy that some studies on the scope of the participatory budget concept and the differentiation of the budget spectrum in the OECD studies, especially for developing countries, are meaningful. Some of the work done by the OECD [19] which aims to be an especially active participant in fiscal transparency is noteworthy. The another study on participatory active citizenship at the budget level earlier by OECD [15] is also one of the first in this regard that contain some developing countries financial matters related to participating budgeting. In this stage the main object of OECD is to contribute to the public budget formation spectrum as especially via it is considered citizens' supports levels. The work of Ganuza and Baiocchi [5], which expresses how a participatory budget will have a global impact level with its internal dynamics, has an important place in the recent studies. Namely, the creation of a harmonized public budget, particularly for developing countries' relations with other developed OECD countries, the internal dynamics of an inclusive budget reform need to be addressed in the direction of the OECD's expectations.

Therefore, these formats to shift the discussion away from the impact of participatory budget should try to answer that why is fairly important that participatory budget's contributing levels. It means that all social demands are channeled through participatory budgets and all the other channels should support these essentially dynamics with ways of civil contacts with the operations actively on the part of the population. And at this point need to also answer this fundamental question that we try to put forth in developing countries throughout OECD's objectives: This action what is fact that it is that aimed to financial development under the name of participatory budgeting and what its spectrum bring to a successful is adoption via these dynamics of budgeting in itself. On the other hand, it should not be missed that the participatory public proposals made require to put forth via civil society 
formations in OECD should be based on institutions inevitably directed towards the correlated financial structures for global participatory. But a participatory budget approach, whatever is this situation expression, can be almost a compound of all these dynamics due to these will have been occurred reasonably beyond these procedures that are based on the participation of "ordinary" citizens allowed to debate the general interests. In this sense, the participatory budget is not only a part of a social plan, but at the same time it is a common sanctions procedure that is draw the attention of common global financial objectives for OECD as common financial sanctions. Certainly, in this participatory spectrum the public decision-making process should be organized on the basis of a multiply socio-economic stage process in which decisions are adopted progressively aimed at publically participatory process. Therefore, for the OECD, a participatory budget concept reaches a concrete common structure with the measurement of public participation and the significance of the cleared impact of socially based financial dynamic.

\section{The Effects of Public Participations to Public Budget Spectrum in OECD}

The public budgets are the financial formations that contain the responsible for the dynamics of public social participation due to have to reflect all the public choices. In this sense, it is not wrong to see the participatory budget concept in a development trend compatible with the social and political development process. In other words, this approach represents a balance between public preferences and publicly productive interests in the budgeting spectrum. The concept of participatory public budgeting can be considered in two financial terms for public spectrum actually related to public budget spectrum especially for developing countries. On the other hand, the participatory budgeting process must also provide global financial integration, and it also provides a framework for co-operation for each public purpose [14]. Because, this process is the opportunity period of public inform that is experienced in the transfer of public authority together with the public agenda directed toward to ensure the participatory budgeting spectrum in the same process.

The effects of public participatory occur in this perfectly point that is related to public decision making process formation, which means the process of involving participatory citizens in decision making concerning the redistribution of public funds for participatory budgeting aimed at the future [11]. Therefore, it is fairly meaningful the participatory spectrum of OECD's decision making related to the scope of decisions whole because of concerning fiscal balances information on the budget-setting process and spending-buying choices priorities. Figure 1 below puts forth the effect process of participatory budgeting being concerned spectrum that is propped up by OECD's accepted and its level of participatory.

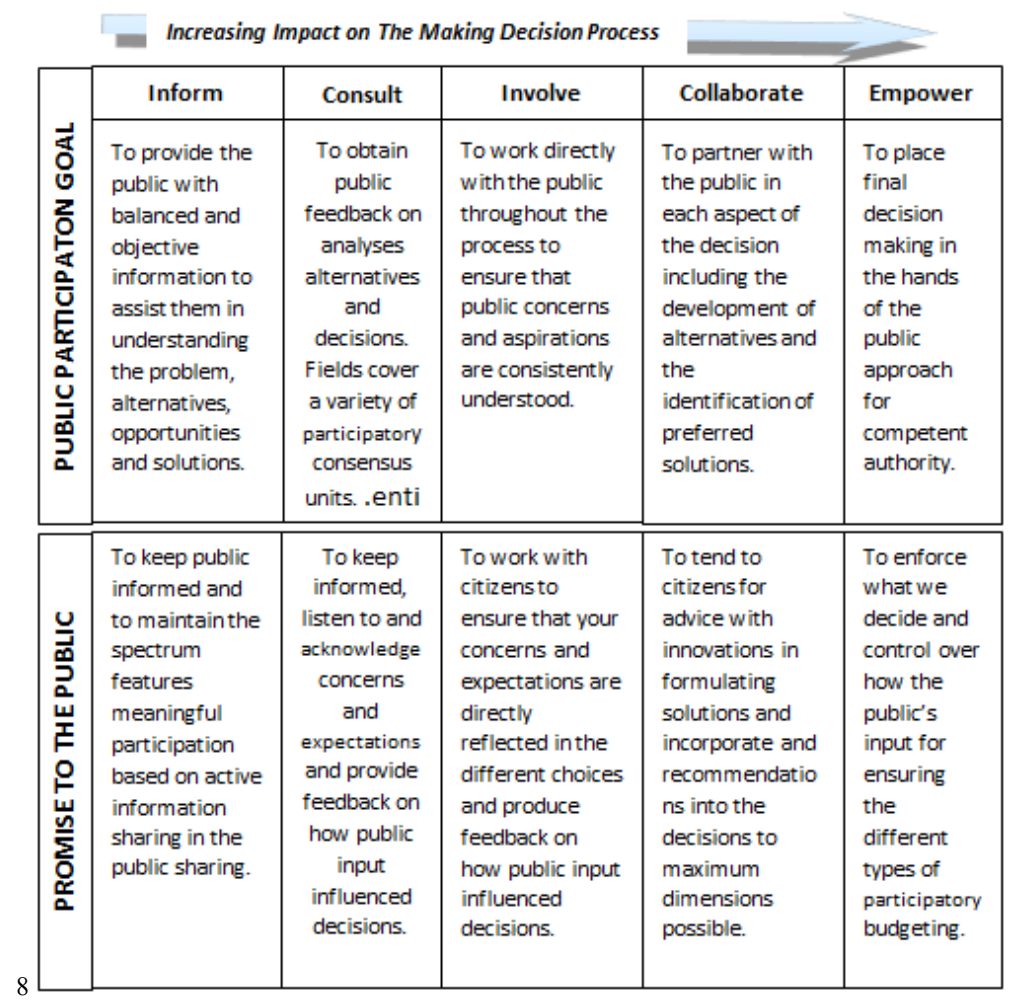

Sources: Public Policy Institute for Wales-(PPIW) (2017), Participatory Budgeting: An Evidence Review, 2017.

Figure 1. The Public Participation Spectrum to Formation Participatory Budgeting 
As in Figure 1. The Public Participation Spectrum to Formation Participatory Budgeting seen on figure 1, the increasing structural impacts on the making decision process effect on the consults via inform process. At this stage, the structural position of participatory budgeting also provides important criteria for the formation of new budgets especially in the associated budget applications. On the other hand, this concept come to mean keeping to promise to the public contributing in the budget process via public's participation spectrum. Providing a balance between public aims and public preferences is the primary purpose of this spectrum [1]. This is because the primary source of authority transfer in the creation of the public budget must be the publically approaches that concept can ensure to share the associated obligations. It should be defined as a meaningful financial transparency audit this financial location aimed at participatory budget process due to determine the effective financial resources [1].

OCED' sanctions are in the same directed line to reach the financial participatory budget objectives. In this context, increasing the effects of public choice decision making bring forth the spectrum features me participation based on active information sharing in the public sharing. Because, active knowledge sharing bring forth the participated expectations and has a meaningful feature to provide feedback on how public input influenced decisions, which produce the main stone of participatory budgets [10]. Throughout this participatory spectrum, the involving concept can be explained as work with citizens to ensure that their concerns and expectations are directly reflected in the different choices and produce feedback on how public input influenced decisions. In fact, it can be said that the level of public impact brings up at this perfectly point in creating a participatory budget, which direct the next stages of participatory formatting. This fact is both a part of public budget dynamics and a structural key that the conclusions effects of budget allocations for public preferences. In the same time as related to process for collaborate is to tend to citizens for advice with innovations in formulating solutions and incorporate and recommendations into the decisions to maximum dimensions possible is an indispensable required approach.

This fact is also considered, as a sharing dimension of spectrum, cover over the entire course of the participatory budgeting. As the last stage for participatory effects can be said that is to enforce what we decide and control over how the public's input for ensuring the different types of participatory budgeting. At this point, decision making process for participatory budgeting contain both fractional dynamics of public different alterations that are belonged to the structural values and the radical reforms components with elements for next years' participatory decisions [2]. Therefore, the effects of participatory budgeting spectrum are the sum of all of the whole spectrum alterations as whole collected dynamics for participatory budgeting. In addition to this, the strengthening of some public units related to authorization transfer aimed at the budget requires clear definition of public authorities. Because the change in the understanding of public authority is probably important for the participatory budget cleared for its effects evaluations [6]. In this way, the participatory budgeting system has a structure which is obliged to be audited at the level of impact of public participation. In this stage it is needed that the formation related to public participation force to this effect level at each stage via open audit. Certainly this the effect level express the accomplishment of participation in budget allocation process in the provided conditions throughout budgeting process [6].

\section{Developing Performance Advantages in Budgeting Stage directed towards OECD for the Participatory Budgeting}

Participatory budgeting obligated to aim or developing performance procedures that include some important budgeting advantage in scope of OECD's objectives. On the other hand, also this concept that is pertaining to participation scales put forth some meaningful risk factors that mean the structural reforms and use performance information in the same terms. In this context, OECD aim to integrate performance information for participatory budget, which contain some recommendation for measuring and assessing performances throughout budget practices especially turned towards developing countries. All these practices to participatory budgeting, first of all, should bring up to meet the accounted performance system aimed at transforming budget formatting via political and local administrative for developing countries [8]. In this framework, it can be said that OECD's structural participatory spectrum put forth in five progressive terms occurred for developing countries.

\subsection{The Implementations Approaches to Participatory Budgeting in OECD and its' Structural Framework}

In practice, the structural framework of a participatory budget reveals also the political change criteria of the countries as well as some radical change proposals for budgeting process. In other words, undoubtedly, there are also significant responsibilities of OECD to address common obligations aimed at ensuring the associated performances and financial sanctions at this related budgeting stage. Surely, before all else the concerned implementation approaches can be expressed in divide some structural terms into classes in its own structural framework.

- First of these, it is improving public budget performance management and budgeting procedures that OECD recommend these structural 
alterations especially for developing countries. And also, this alteration process has seen required by OECD to ensure global financial integrations [9].

- Second, it is determination that budget participatory establishment capacities of government actors in the scope of their authority power [12].

- Third, it is that enhancing social inclusion and participations, which are to focus on budget construction.

- Fourth, it is that institutions policy and legislative forms that support the participatory budgeting process, which put forth to mean public contributing in the making budget process [7].

- $\quad$ Fifth, it is that enabling cross-national tracking of budget openness is approach that is to be supported via all countries for developing countries. The phenomenon has seen inevitably being required by OECD due to ensure financial capital integration for ensuring the different types of participatory budgeting [17].

This process includes also a greater role to the institutional identifying with associated managing implementations that put forth strategic outcomes related to sanctions for OECD's aiming in all entities. At this stage, we should not state that a participatory budget is the most important frame dynamics and results oriented net policies. These policies express also the whole government's planning within reporting on the institutional context which is directed towards the public. Furthermore, it is possible to address these target responsibilities in conjunction with performance expectations created within the structural dynamics of the participatory budget. At this point, the objectives set out by the strategic partnership plan are also a definition of the rudimentary framework that means to support OECD's financial politics for the common development of developing countries. It is meaningful for these dynamical frameworks to determine which contribution levels will clearly influence the objectives in achieving publically-institutional participation in achieving the objectives. Throughout the matter of designing the governments wide system the timing in the budgets allocations to ensure dynamics is important for reforming approaches that mean independent implementations. This critter is meaningful aimed at implementation dynamics and development the potential managerial structures among framework dynamics for a participatory budgeting. And also this structural location encourages an important emphasis as a key that perform actors especially in developing countries within OECD's recommend features [18].

This formation has also a potential to improve the aimed management of participatory budgeting as effective results throughout budgeting practicing as a whole of dynamics. It is very important to state that the next upper tier of this position is the accountability of the applications in this process. Control of all independent expenditures is already a pre-emptive warning for developing countries in the OECD like a corner stone for occurring participatory budgeting [20]. On the other hand, this feature purposes to improve probably declining the underlying causes of poor participatory performance to ensure the effective participatory budgeting throughout the aimed budgeting process. Again, it is important to emphasize that the formation of a participatory budgeting framework dynamics must be based on financial transparency dynamics, which purpose the accountability process of performance-based applications. These transparency dynamics are directly related to put forth both publically accountability and Parliament responsibilities for a meaningful participatory process. In this context, all structural change models can be defined as participatory public budget dynamics. Therefore, performance-based budget implementations incorporate the defining objectives of a participatory budget, as well as qualitative identification of expenditures on public targets. Namely, this structural content also means put forth the main dynamics of the structural framework of a participatory budget into participatory budget implementations.

In the light of all this, a participatory public budget suggests that all financial resources involve the using of public resources in public decision-making processes, and it needs to be in a structural framework should be balancing the comparison of public resources and public objectives. This approach framework should put forth to be directly defined to the standards clearly of performances of budgets [24]. This framework, on the other hand, also forms the framework dynamics of common public programs for the development of budget efficiency performance programs. In addition, we must emphasize that these dynamics of a participatory budgeting express significant macroeconomic dynamism for economic development. Because, the building blocks of public budget are also indicative of a meaningful economic performance. Each dynamic of a participatory budget reveals the economic policy dynamics of OECD countries, and these dynamics, as general accepted components, are considered meaningfully developmental indicators for these countries. In this stage, in particular, we must emphasize that a participatory budget forms a common ground for public priorities and budgetary dynamics within a framework of accountability that is directly responsible to the effective distribution of financial resources for developing countries via these dynamics. Therefore, a performance-based budget for developing countries is shaped by its result-oriented dynamics that cover also results evaluations. However, the implementation budget process that we are referring to in application of the budget is only gaining in effectiveness with the dynamism of the participatory budgeting dynamics, which mention these dynamics [3]. 


\subsection{The Potential Risk and Benefits related to The Participatory Budgeting for Implementations Process}

A participatory budgeting process throughout its implementation undoubtedly involves different benefits and risks for different stages. In other words, this fact is mean that there will have been reformed some budgeting implementations [13]. Since all benefits and risk factors are meaningful at every stage of a performance implementation, it is possible that the potential benefits and risks of the participation process for a participatory budget may also emerge at this stage. It appears that the benefits associated with the accession process are often brought about by increasing the effectiveness of the decision-making process. Decisions processes, generally, need more information for co-ordinations that this manages the structural alteration process [25]. From the beginning to the end of the implementation period of the participatory budgeting, each phase also reveals government practices that have certain standards. This process is meaningful in order to evaluation the budgetary results probably via top-down observing toward to put forth government reports. This framework approach produce also the infrastructure dynamics related more flexibility including more responsibility to reach the aimed performances for participatory budgeting via the evaluation of performance in practicing. In the following figure 2, we can see the risks and benefits components both in top-down and bottom up approaches in participatory budgeting process.

\begin{tabular}{|c|c|c|}
\hline & Benefits & Risks \\
\hline & Increasing Pressure for Reforms & Limiting Flexibility to Reach Results \\
\hline Top-Down & $\begin{array}{l}\text { Uniformity in Approaches and } \\
\text { FrameworkAcross Government }\end{array}$ & $\begin{array}{l}\text { Too Rul-Bound, Performance } \\
\text { Becomes Mere Compliance }\end{array}$ \\
\hline \multirow[t]{4}{*}{ Approaches } & $\begin{array}{l}\text { More Information at the Centre } \\
\text { to Make Decisions }\end{array}$ & $\begin{array}{l}\text { Creating too Reporting Requirements and } \\
\text { Becoming and Expensive Exercises }\end{array}$ \\
\hline & Better Co-ordination and & Failing to Gain the Support of Agencies \\
\hline & Monitoring & $\begin{array}{l}\text { Creating Perverse Incentives and } \\
\text { Distorting Behavior }\end{array}$ \\
\hline & Greater Flexibility & Inertia due to lack of Pressure Reforms \\
\hline Bottom Up & $\begin{array}{l}\text { Capacity to Financial Reforms } \\
\text { to Institutions' Needs }\end{array}$ & $\begin{array}{l}\text { Being more Difficult and Time } \\
\text { Consuming to Implement }\end{array}$ \\
\hline \multirow[t]{3}{*}{ Approaches } & $\begin{array}{l}\text { Enables Greater } \\
\text { Responsiveness to Publicly } \\
\text { Choices and Civil Communities }\end{array}$ & $\begin{array}{l}\text { Lack of Co-Ordination of } \\
\text { Reforms }\end{array}$ \\
\hline & $\begin{array}{l}\text { Encourages Ownership of } \\
\text { Reforms by Agencies }\end{array}$ & $\begin{array}{l}\text { Lack of Information at the } \\
\text { Centre to Make Decisions }\end{array}$ \\
\hline & & $\begin{array}{l}\text { Lack of Consistency in Reform } \\
\text { Efforts and Presentation of Data }\end{array}$ \\
\hline
\end{tabular}

Source: OECD, Performance Budgeting in OECD Countries, 2007.

Figure 2. Potential Risks and Benefits of Performance in the Participatory Budgeting Process

That is an inevitable fact that institutional structural incentives accelerate also the process of target reforms by encouraging, which ensure the approaches contributions of each participant. Potential risks can arise from different structural problems in the implementation process. This means that the structural risks have different effect levels in the considered process. At the first, the defective structural flexibility causes to fall the gain of budget reforms that contribute to form the participatory budget, which increase the reporting feed-back related to the evaluations of budget implementations. This fact causes also to unsuccessful of the decisions making process and meaningless time consuming to implement that result in more increasing risks. In this stage, as a the structural following of participatory budgeting the focused-result budgeting can need to more expensive performance due to lack of co-coordination, and increasing risks to make right decisions result in less public contributing to support incentives and in lack of consistency [21]. And the participatory budgeting can be considered in two terms in order to definite budgeting aimed at to direct financial decision making. Firstly, potential risks have to be supported by the way of monetary policies to budgeting reforms to financial agencies' needs.

This approaches would decrease the probably risk factors and pave the way for more meaningful decisions making. This fact can be accepted the primary corner stone to constitute and maintain the participatory budgeting. Secondly, the responsiveness to publicly choices and civil community options could be increased from top to bottom 
up to ensure the sharpness of participatory levels, which put forth participators' benefits. Secondly, the responsiveness to publicly choices and civil community options could be increased from top to bottom up to ensure the sharpness of participatory levels, which put forth participators' benefits. This structural function facilitates all the coordination monitoring for participatory budgeting implementations and could increase benefits functions related to publicly-institutional participators [4]. The breadth of the knowledge base of a participatory budget is fairly important at the decision-making center, as well as the possible structural changes, in order to reach to the financial integrations in OECD. Asymmetric information fact to ensure the creation of a participatory budget is an absolutely unacceptable phenomenon due to cause the deviations of associated aims. In other words, significant creation disillusionment of asymmetric information in underdeveloped OECD countries is the biggest obstacle to participatory budget integration. As the object of OECD is support for developing countries to ensure the associated common financial values, asymmetric information appears in, as inevitable, these countries' budgets.

This fact can be considered in two terms to the participatory budgets as related to its effects [22]. First, OECD is not sufficient accomplishment level to reach the aimed integrations developing countries, which mean unable greater responsiveness to publicly choices and civil communities. Secondly, OECD could not take on the sufficient responsibility to overcome deal with the unconsidered perverse incentives and deviations financial behavior in scope of new approaches. In this case, the benefits elements that are shown in Figure 2 cannot be sustained in a balanced structure to support to developing countries. This is because benefits and risk distributions are more likely to fairly negatively affect less developed countries in terms of the level of development of the countries. In this case, OECD, as a developing cooperation unity, needs more the structural analysis related to the deduction process to ensure the induction. For this reason, the existence of participatory budgeting also requires that the countries be subject to these analyses at different development levels from time to time, and it justifies the responsibility analysis of each financial resource for the budget. Certainly, this fact form the essence core of participatory budgeting related to OECD's requirements [26].

\section{Conclusions}

The phenomenon of participatory budgeting presents an important financial framework for OECD member countries. In this context, the general principles of participation, including the general principles of the OECD and all Member States, constitute the dynamics of a participatory work for the countries at the same period. Developing countries, particularly in relation to their different levels of development, represent different budgetary commitments, but the main principle is an out of growth of responsibilities to ensure participatory process. The main principles of participatory cover also the budgeting performance that is meaningful in allocation evaluating. This fact ensures clarity the clearer financial resources in evaluating period including financial reforms. As developing countries in OECD are needed financially supports, in this stage, in order to both ensuring budget balances and growing participatory via public audits. On the other hand, it should also be emphasized that a participatory budgeting is an important analytical ground in the public electoral paradigm. Increasing decision responsibilities for the public budget are also a key element of the reflection of public options on the budget via publically effects.

In other words, the increasing level of participation is directly proportional to the public responsibilities. The fact that developing countries are not sufficient effect levels throughout at the desired level in public decision-making mechanisms could be understood to be a result of not being able to reflect the financial participation to the decision processes at the desired level. The lack of sufficient institutional qualifications is the most problem to reach the desired participatory levels in developing countries. As this aim OECD's general developing units should provide again the decision making process framework via the associate participatory values. The goal in process is to achieve better ordination and monitoring that contribute positively to the participatory process. But all the structural differences create difficulties to reach the desired participatory levels especially in developing countries, and that phenomenon should be analyzed by OECD for all members if the main goals provide the participatory budgeting. Therefore, determination of financial responsibilities by the OECD taking place in the process of possible financial reforms for developing countries requires socio-economic infrastructure reforms that primarily support participation.

\section{REFERENCES}

[1] Ahmad, Raza and Weiser, Erin Thébault (eds.) (2006), Fostering Public Participation in Budget-Making: Case Studies from Indonesia, the Marshall Islands, and Pakistan, Publication Stock No. 101306, Asian Development Bank, The Asia Foundation, 2006.

[2] Cabannes, Yves (2014), Contribution of Participatory Budgeting to Provision and Management of Basic Services Municipal Practices and Evidence from the Field, Working Paper September 2014, London: International Institute for Environment and Development, 2014.

[3] Dias, Nelson (2014), Hope for Democracy - 25 Years of Participatory Budgeting Worldwide, São Brás De Alportel: The Service Agency Communities in One World, 2014. 
[4] [Fölscher, Alta (2007), "Participatory Budgeting in Central and Eastern Europa" in Participatory Budgeting, Anwar Shah (Ed.), The World Bank Washington D.C.: The World Bank-The Public Sector Governance and Accountability Series, 2007.

[5] Ganuza, Ernesto and Baiocchi, Gianpaolo (2012), "The Power of Ambiguity: How Participatory Budgeting Travels the Globe", Journal of Public Deliberation, Vol. 8, Iss. 2, Article 8, pp. 1-12.

[6] Gilman, Hollie Russon (2016), Engaging Citizens: Participatory Budgeting and the Inclusive Governance Movement within the United States, Ash Center Occasional Papers, Ash Center for Democratic Governance and Innovation, Harvard Kennedy School, January 2016.

[7] Goldfrank, Benjamin (2007), "Lessons from Latin America's Experience with Participatory Budget", in Participatory Budgeting, Anwar Shah (ed.), The World Bank Public Sector Governance and Accountability Series, Washington D.C: The World Bank the International Bank for Reconstruction and Development, 2007.

[8] Gonçalves, Sonia (2014), "The Effects of Participatory Budgeting on Municipal Expenditures and Infant Mortality in Brazil", World Development, Vol. 53, pp. 94-110, 2014.

[9] Heimans, Jeremy (2002), Strengthening Participation in Public Expenditure Management: Policy Recommendations for Key Stakeholders, OECD Development Centre, Policy Brief No. 22, 2002

[10] Iloh, Emeka and Nwokedi, Michael Eberechukwu (2016), "Budget Processes and Participatory Budgeting in Nigeria: Lessons from Latin America", Journal of Arts and Social Sciences, 5(1), 2016, pp. 135-154.

[11] Irvin, Renee and Stansbury, John (2004), "Citizen Participation in Decision Making: Is It Worth the Effort?", Public Administration Review, 64(1), February 2004, pp. 55-65.

[12] Moynihan, Donald P. (2007), "Citizen Participation in Budgeting: Prospects for Developing Countries", in Participatory Budgeting, Anwar Shah (ed.), The World Bank Public Sector Governance and Accountability Series, Washington D.C: The World Bank the International Bank for Reconstruction and Development, 2007.

[13] Mullen, Patrick R. (2006), "Performance-Based Budgeting: The Contribution of the Program Assessment Rating Tool", Public Budgeting \& Finance, Winter 2006, pp. 79-88.

[14] Muse, Sulaimon Adigun and Narsiah, Sagie (2015), "The Politics of Participatory Budgeting in Nigeria: A Case
Study of Community Development Associations (CDAs)", Journal of Human Ecology, 50(3), June 2015, pp. 263-269.

[15] OECD (2001), Citizens as Partners, Paris: OECD, 2001.

[16] OECD (2007), Performance Budgeting in OECD Countries, 2007.

[17] OECD (2014), OECD Principles of Budgetary Governance, OECD Senior Budget Officials, July 2014.

[18] [OECD (2015-a), Principles of Corporate Governance, OECD: OECD Publishing Paris, 2015.

[19] OECD (2015-b), OECD Best Practices for Budget Transparency, http://www.oecd.org/ gov/budgeting/best-practices-budget-transparency.htm, (06.06.2018).

[20] OECD (2016), Development Co-Operation Report 2016: The Sustainable Development Goals as Business Opportunities, OECD: OECD Publishing Paris, 2016.

[21] Opawole, Akintayo, and Babatunde, Solomon Olusola (2012), "Evaluation of the Contribution of Construction Professionals in Budgeting for Infrastructure Development in Nigeria", International Journal of Sustainable Construction Engineering \& Technology, 3(2), December 2012, pp. 83-95.

[22] Pateman, Carole (2012), "Participatory Democracy Revisited", Perspectives on Politics, Vol.10, No: 1, (March 2012), pp. 7-19.

[23] Public Policy Institute for Wales-(PPIW) (2017), Participatory Budgeting: An Evidence Review, August, 2017.

[24] Shah, Anwar (2007), "Overview", in Participatory Budgeting, Anwar Shah (ed.), The World Bank Public Sector Governance and Accountability Series, Washington D.C: The World Bank the International Bank for Reconstruction and Development, 2007.

[25] UN-HABITAT-United Nations Human Settlements Programme (2008), Participatory Budgeting in Africa: A Training Companion with Cases from Eastern and Southern Africa, Volume I: Concepts and Principles, HS number: HS/969/08E, United Nations Human Settlements Programme and Municipal Development Partnership for Eastern and Southern Africa, 2008.

[26] Wampler, Brian (2000), A Guide to Participatory Budgeting,

http://www.partizipation.at/fileadmin/media data/Downloa ds/themen/A_guide_to_PB.pdf, (24.06.2018).

i JEL Codes: H11, H23, H24, H61, H83. 